\section{Phoenix prepares for work after safe landing on Mars}

After a dramatic deceleration through Mars's thin atmosphere, NASA's Phoenix mission is set to go to work. It landed on 26 May about 30 kilometres from its intended set-down point in Mars's northern plains. Its arrival marks the first successful 'soft' landing on Mars - a gentle setting down by means of retrorockets, as opposed to a crash-bang-wallop arrival swaddled in airbags - since that of Viking 2, more than 30 years ago.

"This is a scientist's dream, right there on this landing site," says mission principal investigator Peter Smith of the University of Arizona at Tucson, looking at pictures that show distinctive polygonal patterns on the surface (see right). Such patterning is one of the lines of evidence suggesting that Phoenix's digging arm should be able to unearth ice from the subsurface. The ice may record changes in the martian climate, and could contain organic molecules.

Mission scientists will spend a few days checking and calibrating instruments before starting to take samples for mass spectrometry and chemical analysis.

The successful descent was documented by a phenomenal image of the lander's parachute and shell (see inset), taken by the HiRISE camera on NASA's Mars Reconnaissance Orbiter during the descent from a distance of around 760 kilometres.

\section{Norway's first Kavlis take on Nobel prizes}

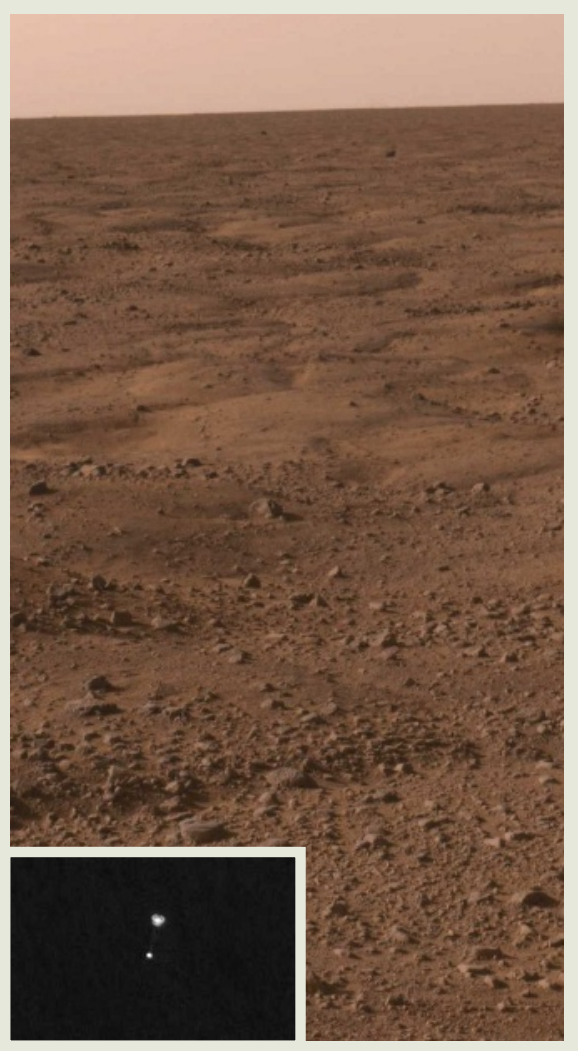

Research on quasars and carbon nanotubes was recognized by the judges of the inaugural Kavli Prizes, announced on 28 May in Oslo. Maarten Schmidt of the California Institute of Technology, and Donald Lynden-Bell of the University of Cambridge in the UK, are joint recipients of the astrophysics prize for their pioneering work on quasars. This "dramatically expanded the scale of the observable Universe and led to our present view of the violent Universe in which massive black holes play a key role," according to the Kavli committee.

Louis Brus of Columbia University in New York and Sumio Iijima of Meijo University in Nagoya, Japan, share the prize for nanoscience for their respective discoveries of colloidal semiconductor nanocrystals (quantum dots) and carbon nanotubes. And the neuroscience prize - awarded for their "discoveries on the developmental and functional logic of neuronal circuits" - went to Pasko Rakic of Yale University School of Medicine in New Haven, Connecticut, Thomas Jessell of Columbia University and Sten Grillner of the Karolinska Institute in Stockholm. The three US\$1-million prizes are to be awarded every two years. 